\title{
Moneyball for State Regulators
}

\section{Citation}

Edward L. Glaeser \& Cass R. Sunstein, Moneyball for State Regulators (Harvard John M. Olin Discussion Paper Series Discussion Paper No. 783, July 2014, Nat'l Aff., Summer 2014).

\section{Published Version}

http://www.law.harvard.edu/programs/olin_center/papers/pdf/Sunstein_783.pdf;http:// www.nationalaffairs.com/doclib/20140620_GlaeserSunstein.pdf

\section{Permanent link}

http://nrs.harvard.edu/urn-3:HUL.InstRepos:20277093

\section{Terms of Use}

This article was downloaded from Harvard University's DASH repository, and is made available under the terms and conditions applicable to Other Posted Material, as set forth at http:// nrs.harvard.edu/urn-3:HUL.InstRepos:dash.current.terms-of-use\#LAA

\section{Share Your Story}

The Harvard community has made this article openly available.

Please share how this access benefits you. Submit a story.

\section{Accessibility}




\section{HARVARD}

JOHN M. OLIN CENTER FOR LAW, ECONOMICS, AND BUSINESS

MONEYBALL FOR STATE REGULATORS

Edward L. Glaeser

Cass R. Sunstein

Published in National Affairs, Issue 20 (Summer 2014)

Discussion Paper No. 783

$07 / 2014$

Harvard Law School

Cambridge, MA 02138

This paper can be downloaded without charge from:

The Harvard John M. Olin Discussion Paper Series: http://www.law.harvard.edu/programs/olin_center/

The Social Science Research Network Electronic Paper Collection: http://ssrn.com/abstract=2418306 
Preliminary draft $3 / 29$

Forthcoming National Affairs

All rights reserved

\title{
Moneyball for State Regulators
}

\section{Edward Glaeser" and Cass R. Sunstein ${ }^{* *}$}

\begin{abstract}
For over thirty years, Republican and Democratic presidents have required executive agencies to assess the costs and benefits of significant regulations, and to proceed only if the benefits justify the costs (to the extent permitted by law). The goals of the resulting processes have been to constrain unjustified regulation, to promote interagency coordination, and to allow a degree of centralized management of what can be a cumbersome bureaucratic apparatus. Unfortunately, state and local governments sometimes impose costly requirements, undisciplined by careful analysis of their likely consequences. New institutions at the state level, producing such analysis, could be highly beneficial, replacing processes sometimes driven by anecdotes, dogmas, emotions, and interest-group pressures with a form of Regulatory Moneyball.
\end{abstract}

\section{The Basic Proposal}

Should state and local governments ask whether the benefits of regulations exceed their costs? Sensible regulatory requirements can reduce illnesses and accidents, protect the environment, and maintain quality of life. But when regulation is onerous and poorly designed, it can cause serious harm -- overwhelming small businesses, reducing economic growth, eliminating jobs, squelching innovation, and causing serious hardship. The goal of all levels of government should be to strike the right balance, with careful consideration of the track record of old rules and the likely consequences of new regulatory requirements (Greenstone, 2009).

For over four decades, and under both Democratic and Republican presidents, the national government has attempted to achieve that goal and to discipline the regulatory process. It has done so by requiring detailed analysis of both the costs and benefits of regulations - and by allowing agencies to go forward, and to burden the private sector, only if the benefits justify the costs (Sunstein, 2013a).

Our principal contention here is that state and local governments should do exactly the same thing. In today's world, the need for regulatory discipline from state and local governments, and for careful cost-benefit analysis, is especially pressing. Such

${ }^{*}$ Fred and Eleanor Glimp Professor of Economics, Harvard University.

${ }^{* *}$ Robert Walmsley University Professor, Harvard University. Sunstein was

Administrator of the Office of Information and Regulatory Affairs from 2009 to 2012. 
governments are often responsible for requirements that many view as burdensome, unjustified, and harmful; permitting and occupational licensing requirements are prominent examples. Perhaps this view of local regulation is unduly negative, but subnational governments generally lack an institutional mechanism even to evaluate the negative claims. Cost-benefit analysis, undertaken by relevant personnel with real authority, would provide that mechanism. Properly conducted and fairly applied, it would also operate as a safeguard against the power of interest groups, who often seek to enlist government on their behalf. Cost-benefit analysis is not intrinsically anti, or pro, regulation. Nor should it be seen as an effort to put policy judgments into an arithmetic straightjacket. It is simply a tool that helps produce good regulations and avoid bad ones.

Indeed, we would go further. In 2011, the Obama Administration, with bipartisan support, called for an ambitious process through which federal agencies would periodically evaluate their existing rules, with the goal of eliminating or streamlining them when cost-benefit analysis suggested that elimination or streamlining was warranted (Sunstein, 2013a). The "regulatory lookback," as it is called, has produced over 500 reform proposals, and it is saving billions of dollars each year (ibid.). While the lookback remains a work-in-progress at the national level, there is every reason to think that states should be engaging in lookbacks of their own, eliminating and streamlining burdensome requirements.

In some ways, states might be able to go far beyond the efforts of national government, because of their relative capacity and incentive to innovate. We envision a kind of competition at the state level, not to produce a mutually destructive "race to the bottom," but to activate creative thinking about how to institutionalize regulatory simplification, freeing up the private sector while also improving, and certainly without jeopardizing, public safety, health, the environment, and quality of life.

\section{Regulatory Moneyball}

Relying on analysis of costs and benefits, instead of intuitions and anecdotes, might seem obvious, a little like relying on sense rather than nonsense. But the temptation to favor intuition over information is strong, and it leads to serious mistakes in private and public life. Recall Moneyball, Michael Lewis' best-selling 2003 book (Lewis, 2003), which was the basis for the hit film of the same title, starring Brad Pitt. Lewis tells the story of Billy Beane, the general manager of the Oakland Athletics baseball team. With the help of his statistics-obsessed assistant, Paul DePodesta, Beane brought the oncelowly Athletics into the top tier of baseball teams, and wound up transforming professional baseball, by substituting empirical data for long-standing dogmas, intuition, and anecdote-driven judgments. Lewis makes clear the difference between the two approaches in this exchange about a particular player between Beane, DePodesta, and a veteran baseball scout:

"The guy's an athlete, Billy," the old scout says. "There's a lot of upside there." "He can't hit," says Billy. "He's not that bad a hitter," says the old scout... P Paul reads the player's college batting statistics. They contain a conspicuous lack of extra 
base hits and walks. "My only question is," says Billy, "if he's that good a hitter why doesn't he hit better?"

In the past, too many regulators, state as well as federal, have been tempted to listen far too much when they were told that "the public is very worried," or that "polls show that the majority of people strongly favor protection against air pollution," or that "the industry has strong views," or that "the environmental groups will go nuts," or that "if an accident occurs, there will be hell to pay." None of those observations addresses the real question, which is what policies and regulations would achieve. All over the United States, regulatory systems need their own Billy Beanes and Paul DePodestas, carefully assessing what rules will do before the fact and testing them after the fact (Sunstein, 2013a).

There is a connection here with Daniel Kahneman's celebrated distinction, drawing on many years of psychological research, between fast thinking and slow thinking (Kahneman, 2011). People can often make mistakes by thinking fast and relying on gut instinct. In some cases, intuitions and emotions drive judgments, potentially producing bad outcomes. The moneyball approach - represented by a quantitative costbenefit approach to regulation - imposes slow thinking. It represents a kind of institutionalization of a deliberative process, operating as a check on unreliable intuitions (whether they are favorable or unfavorable to proposed initiatives). In the context of state and local regulation, this kind of check can be exceptionally important.

Skeptics might object that debates about regulation are really about values, not facts. According to this view, when people disagree about a rule that would protect clean air or increase highway safety, it is because of what they most value, not because of disagreements about the evidence. We agree that on some of the largest issues, values and predispositions do play a critical role (Kahan, 2010). Cost-benefit analysis will do little to settle the debates surrounding the regulation of first-term abortions.

At the same time, it is easy to overstate the point. For example, most people's values do not lead to a clear judgment about whether to require small businesses to obtain permits to engage in certain activity, or what kinds of licensing requirements should be imposed on hairdressers or interior designers, or what kinds of obstacles should be placed in the way of those who seek to compete with traditional taxi companies. Values alone cannot guide the decision about whether to reduce levels of ozone in the ambient air from 75 parts per billion to 70 parts per billion or, for that matter, to 20 parts per billion. To evaluate such proposals, factual evidence is indispensable. Even where value divisions are great, numbers can help. There are cheap and expensive rules that promote public safety, and we all should prefer the less costly options.

When the evidence is clear, it will often lead people with different values to the same conclusion. If a regulation would save many lives and cost very little, people are likely to support it regardless of their party identification, and if a regulation would produce little benefit but impose heavy costs, citizens are unlikely to favor it regardless of their abstract ideas about government. No less than the national government, state and 
local governments should be moving in the direction of Regulatory Moneyball, making choices about rules on the basis of careful analysis rather than intuitions, anecdotes, dogmas, and impressions.

\section{History}

To understand our proposal, some history is in order. At the national level, the modern era of regulatory review began in 1981, when President Reagan issued, during his first weeks in office, Executive Order 12291. That historic order, effectively binding on the executive branch, imposed two sets of requirements. The first were procedural; the second were substantive.

Reagan's procedural requirement directed agencies to submit their regulations to the Office of Management and Budget (OMB) for approval (DeMuth and Ginsburg, 1986). Operating within OMB, and created by the Paperwork Reduction Act, the Office of Information and Regulatory Affairs (OIRA) gained a great deal of authority over the regulatory process. Subject to the ultimate power of the President himself, OIRA could effectively decline to authorize agencies to impose regulations on the public. Of course, it was understood that OIRA would not be acting unchecked or on its own. Its decisions would be reached in close concert with others in the executive branch, including technical specialists of various kinds - an important point to which we will return.

Reagan's substantive requirement directed agencies to produce careful analyses of the costs and benefits of regulations, and to proceed only if the benefits outweighed the costs (subject to legal mandates issued by Congress) (ibid.). Under this approach, an agency could not finalize a regulation protecting worker safety if the costs were $\$ 700$ million and the benefits $\$ 90$ million (unless the law required it to do so). The importance of this constraint could not easily be overstated. It was designed above all to ensure that agencies do not think in terms of interest groups, dogmas, anecdotes, or intuitions -- and instead that they investigate the actual consequences of the actions that they propose to take. Cost-benefit analysis is best understood as an effort to give officials and the public in general a sense of the anticipated human consequences of alternative courses of action.

As part of the requirement to balance costs and benefits, Reagan also directed agencies to "maximize net benefits." This direction meant that even if a proposed approach - involving, say, environmental protection -- would have net benefits of $\$ 100$ million, agencies could not proceed if another approach (whether less or more stringent) had net benefits of $\$ 200$ million (again, subject to mandates issued by Congress). Of course, the task of monetizing costs and benefits can be challenging - another important point to which we shall return.

In imposing these requirements, Reagan was motivated by three distinct concerns. The first, of particular relevance to our thesis here, involved purely economic considerations. In his view, many regulations could have harmful effects (including 
adverse effects on businesses large and small, consumers, and employment), and it was important to ensure that if the government was imposing significant costs, it was creating significant benefits as well. A clear goal was to scale back the production of new regulatory requirements - not at all by grinding them to a halt, but by ensuring that they had strong, evidence-based justifications.

The second and very different motivation, also relevant to our thesis, involved political control. During the early days of the Reagan Administration, there was a widespread view that the sheer number of regulatory agencies created a serious problem, which involved presidential management of their actions and indeed of the administrative state in general. Even if their heads were presidential appointees, some of their regulations might not reflect the principles or priorities of the President. (In some cases, it might reflect the principles or priorities of their staffs.) OIRA review, undertaken with close reference to presidential principles and priorities, could supply a corrective. A central goal, then, was to ensure hierarchical control of the operations of regulatory agencies, with close reference to the beliefs and commitments of elected officials, and above all, one in particular: the President of the United States.

The third concern involved interagency coordination (Sunstein, 2013b). No agency has a monopoly on knowledge or wisdom, and the decisions of any single agency could benefit from the expertise of others. In this light, the OIRA process was understood to have a coordinating function, ensuring that multiple actors, with their own areas of specialization, could bring their knowledge to bear. For example, the Small Business Administration (SBA) knows a great deal about the effects of regulatory requirements on small business, and OIRA could help to be a mechanism by which the views of the SBA would be taken seriously.

Under President Reagan and his successor George H.W. Bush, OIRA review proved to be highly controversial, especially among people who had far more enthusiasm for regulatory requirements than Presidents Reagan and Bush did. In their view, regulatory review operated as an unfortunate obstacle to desirable initiatives (McGarity, 2013). It was therefore important, and indeed historic, that President Bill Clinton essentially approved the Reagan approach with Executive Order 12866, issued in 1993.

With that Executive Order, President Clinton did inaugurate some important changes. For example, he reduced the number of rules subject to OIRA review, limiting it to those with a significant economic impact ( $\$ 100$ million annually) or raising serious questions of law or policy. He said that the benefits must "justify" rather than "outweigh" the costs, thus allowing room for consideration of nonquantifiable values (such as protection of privacy). He imposed a set of disclosure requirements on OIRA and made it clear that in the event of conflict, the Vice President (and ultimately the President) would make the final decision. But the larger message was that Clinton embraced, essentially wholeheartedly, the very concerns that had led Reagan to act twelve years previously.

Subsequent presidents have agreed (Sunstein, 2013b). Indeed, President Obama has taken particularly ambitious steps to ensure careful balancing of costs and benefits, 
not least by calling for quantification of both (wherever feasible) and by insisting on scientific integrity (and hence a clear separation between political judgments and judgments about economic values) (ibid.; see Appendix). As we have noted, President Obama went well beyond his predecessors in calling for retrospective as well as prospective analysis. The effort to reassess existing requirements, and to simplify or remove them, is now an established part of the structure of national regulation.

\section{A Rare Consensus, With Challenges}

Notwithstanding their bipartisan endorsement, no one believes that these various requirements have produced the best of all possible worlds. Some people think that federal regulatory requirements are excessive, even wildly excessive, and that the OIRA process has not done nearly enough to constrain them. Other people believe that OIRA has been far too aggressive and that it has slowed down, or stopped, a range of regulations that would reduce illnesses, accidents, and deaths (Heinzerling, 2013). But it is widely agreed that the process of regulatory review, with its insistent focus on costs and benefits, has made the situation far better than it would otherwise be, though more empirical work needs to be done on that question (for one review, see Morgenstern, 1987).

The shared agreement stems from an appreciation of the procedural and substantive innovations that Reagan inaugurated (ibid.; Sunstein, 2013b) - innovations that, as we shall see, have clear implications for state regulators. If the Environmental Protection Agency is issuing a rule that affects the transportation sector, or that has an impact on farmers, it is important and even indispensable for the Department of Transportation, or the Department of Agriculture, to offer its views. Interagency coordination, aggregating diverse information, is indispensable, and the OIRA process helps to ensure that it occurs. This point suggests that in the OIRA process, OIRA itself is often a convener far more than the central actor. It will aggregate information and take steps to ensure that dispersed knowledge is brought to bear on regulatory choices.

In recent years, the process of information aggregation has emphatically involved the public - an important consideration for state government as well. At the national level, the Administrative Procedure Act (APA) generally requires a public comment period for regulations. (Most states have their own APAs.) It is not always the case, however, that agencies ensure a robust opportunity for public comment, or that they pay close attention to the comments that they receive. As it now operates, the OIRA process is very much focused both on receiving public comments and on ensuring that they receive careful attention. Because members of the public often have information that agencies lack, the result of the comment period is to reduce the risk of error, in a tribute to longstanding economic attention to the dispersed knowledge of the public.

The OIRA process also promotes managerial goals, including consistency with the views of national leaders, above all the President himself. (The parallel with state government should be clear, because governors, among others, often seek to oversee their own bureaucracy, sometimes with imperfect success.) If an agency wants to pursue a path 
that conflicts with high-level priorities, the process will ensure that the conflict will come to the agency's attention. Suppose, for example, that economic growth is a high priority, or homeland security, or implementation of the Affordable Care Act. It is not only legitimate but also extremely important to ensure that the President can manage the operations of his own team.

In our view, however, the most important point involves economic considerations. Even in ordinary economic times, it is valuable and even necessary to ensure that when agencies impose significant costs, they do so for good reasons. In periods of economic difficulty, when stringent regulation can impose an especially serious toll on businesses, consumers, and workers, the case for ensuring that benefits justify costs is even stronger. For example, there is a detailed literature in the relationship between regulation and job loss (Coglianese et al., 2014), and while any particular assessment requires a great deal of technical work, there is no question that some regulations cost jobs. And whenever regulations impose high costs, they can increase prices as well, straining consumer budgets and reducing consumer purchases as well (a particularly serious problem for the poor).

As we have noted, the calculation of costs and benefits can create serious challenges. But economists have developed technical methods to meet those challenges, and those methods have long been in use at the national level (Sunstein, 2014). For example, the assessment of costs, or at least the range of likely costs, is often feasible, at least if regulators work with those who are likely to be affected (while also giving their assessment a careful reality check). When regulations have purely economic benefits as, for example, through energy efficiency requirements that reduce the costs of appliances - the benefits calculation is also straightforward. To this extent, calculation of benefits and costs poses empirical challenges that economists are trained to meet.

To be sure, the underlying questions become harder when regulation would reduce risks to life and health. How can we know whether an environmental rule, or one involving traffic safety, would save 200 lives per year, or twenty, or two? And even if we know, how can we turn those figures into monetary equivalents? The first question presents potentially difficult questions of fact. The good news is that it is often possible to gain traction on such questions, at least by identifying ranges (Sunstein, 2014).

The second question may be even more controversial. But unless we try to answer it, we will be in a bad position when we must decide whether and how to proceed. Indeed, any judgment about whether to proceed, and how, will depend on an implicit assignment of monetary values: If you are willing to issue a regulation costing $\$ 200$ million to save 200, but not to save two, you are making such an implicit assignment. And here too, there is good news. Technical methods, based on decades of research, are available to help monetize risks to life and health (Sunstein, 2014). And where such methods are not available, OIRA has developed strategies to help decide how to resolve seemingly intractable dilemmas (ibid.). 
We have noted that no one thinks the current regulatory system is ideal at the national level, but that most informed observers agree that it is far better than it would be without the OIRA process. But OIRA itself is often asked the following question: What are you going to do about costly, burdensome, unjustified requirements at the state level? Because of the nature of our federal system, OIRA has no sufficient answer to that question. But it is an excellent one. The real impetus for state and local regulatory review must come from state and local governments.

\section{The State of State and Local Regulation}

Boston's Dudley Square is the city's busiest bus stop, with 30,000 passengers passing through daily (CBRE/Grossman Retail Advisors, 2013). Eighty thousand people live within a mile of the stop. Yet the area is an entertainment vacuum, with almost no restaurants, clubs or coffee houses. The lack of local fun is not merely an inconvenience to local residents looking for enjoyment, but also represents a dearth of service sector jobs that are badly needed in the neighborhood.

When local leaders are asked about the missing cafes, they mention Boston's difficult regulatory regime (Gaffin, 2013). The state legislature has capped the number of liquor licenses in Boston since the 1930s, and as a result, the price for a license can top $\$ 300,000$ (The Boston Globe, 2013). Any “common victualer" will need a bevy of licenses, including Certificates of Occupancy, health, and safety licenses. If a bar wants a television set that exceeds 27 inches, it will need an entertainment license, and if it wants to go from two to three televisions, that will require an added trip to the licensing board. Occupational licensing is pervasive, and it covers a wide range of people, seeking to become hairdressers, interior designers, dental assistants, manicurists, and much more.

There are reasons behind all of these rules, which aim to limit public nuisances and health hazards, but together they can have serious adverse effects and even kill a neighborhood. Moreover, none of these rules have ever been subject to the kind of analysis performed daily as a result of the OIRA process. Many studies have found that entrepreneurship is the life's blood of urban regeneration (Glaeser, Kerr, and Kerr, 2012), which means that new business regulations that stymie entrepreneurship can have particularly large costs.

Although most academic and public attention has been devoted to federal regulation, there is no question that state and local controls have a large impact, and have done so for a long period. William Novak's (1996) eye-opening history of $19^{\text {th }}$ century regulation in the United States reminds us that even in the allegedly laissez-faire years of the Gilded Age, American states and cities imposed a wide array of rules on their citizens. Indeed the Federal government - in the form of the Supreme Court - often limited local attempts at regulating industry, as it did most famously (or infamously) in Lochner v. New York (1905). Federal regulations rose dramatically over the $20^{\text {th }}$ century, 
but those rules did not eliminate the tendency of localities to regulate businesses and households as well.

Boston is not uniquely strict in its new business regulations. For example, any New York State grocery or restaurant that plans to sell 3,000 pounds of milk monthly must obtain a separate milk dealer license. Blue laws that restrict business activity on Sunday are of ancient provenance (the Emperor Constantine promulgated one in 321), and they remain in force in many parts of the country. Local ordinances banning cigarette smoking have become ubiquitous over the past decade.

Local businesses are also regulated because of their potential to create congestion or other nuisances. For example, installing gas ovens in New York City requires a separate fire department inspection, using liquefied carbon dioxide or petroleum gases requires separate permits, and commercial vehicles face a separate city tax. When it comes to cooking, there are also, of course, state and local rules that directly affect household behavior. Backyard barbecues are regulated in many communities.

In some states, transportation is highly regulated, including mandatory use of seat belts and car seats for children. State regulations of automobiles can have a national impact. California's car market is so large that its emission standards influence the national production decisions of car manufacturers. Some states, but not others, require costly annual inspections, even in newer cars that carry little risk. Our point is not to suggest that any or all of these regulations are wrong -- only that they should be seriously evaluated (and often are not). Moreover, the differences that exist across states suggest that either the stringent states or the more laissez-faire areas are making serious errors.

Local governments are often just as assiduous about regulating new housing as they are in regulating new businesses and automobiles. Evidence seems to suggest that restricting the quantity of new construction makes places less affordable and thus adversely affects prospective homeowners (Katz and Rosen, 1987; Glaeser, Gyourko, and Saks, 2005). Rules that limit construction can effectively zone out poorer residents from areas, thus creating segregation via regulation.

Housing regulations are ancient and often motivated by obvious risks; Boston banned thatched roofs in 1630, the year of the city's founding, in the wake of an urban fire. New York City's Tenement Acts first focused on fire risk in 1867 and then moved to mandate better ventilation and light in the interest of reducing contagious disease. Structural safety continues to be one reason that states and localities restrict new construction with building codes, but over the years, new rationales emerged for limiting new development.

Single-use, or Euclidean zoning, was also originally justified, in part, as a tool to keep noxious industrial activities away from residential dwellings. New York City's landmark zoning code of 1916 mandated setbacks to ensure the flow of light, motivated in part by the massive shadow cast when the Equitable Building was completed in 1915. After the destruction of New York's old Penn Station, a new era of landmarks 
preservation emerged where individual structures or even entire neighborhoods are placed under heavy supervision to limit change.

Perhaps the most potent form of current land use regulations is the restriction of minimum lot sizes, which can range from small slivers of land to 60 acres in places like Marin County. The motivation for these laws varies, ranging from reduction of congestion or local expenditures to preservation of a traditional rural character. But there is little doubt that mandating a minimum amount of acreage ensures less construction in high demand areas (Glaeser and Ward, 2007) and if the laws of supply and demand still operate, this reduced supply will also raise prices.

The web of environmentally oriented local regulations illustrates the diverse geographies and government actors that can all play a role in crafting local regulations. Massachusetts' rules protecting wetlands originate in state legislation, such as Title XIX, Chapter 131, Section 40. But the Commissioner of Environmental Protection has significant leeway in administering and interpreting the law. Moreover, many communities in eastern Massachusetts have gone beyond the state standard and enacted more stringent local definitions of wetlands (Glaeser and Ward, 2007).

Yet it is far from obvious that all environmentally motivated rules are actually good for the environment, and that question should be asked with care. Glaeser and Kahn (2010) document that carbon emissions are far lower in coastal California than elsewhere in the U.S., because the climate is so mild. When California's environmentalists enact laws that prevent local building, they are not stopping development at the national level. They are ensuring only that the development will happen elsewhere, very possibly in some place where commutes will be further and energy use in air conditioning or heating will be higher. Local environmental impact reviews are incomplete, because they evaluate only the impact on the local environment if the project proceeds locally, not the broader impact on the environment if the project is displaced to another area.

Inadvertent environmental side effects are only one reason why critics of local land use regulation suggest that they may have gone too far. This claim proceeds with a view that suggests that localities are motivated by extremely parochial interests ("NIMBYism"), and consider only the interests of local property owners, not the interests of would-be buyers who are priced out because of restricted supply. Indeed, Glaeser and Ward (2007) produce evidence suggesting that localities are too restrictive, even relative to the goal of maximizing total land values, perhaps because of a strong bias towards the status quo. Glaeser, Gyourko, and Saks (2005) attempt to estimate the adverse social effects of building up in Manhattan and find few benefits that can justify the regulatory limits placed on new construction.

If the potential downside of regulating housing is that the housing is too expensive, one potential downside of regulating businesses is that wages will be too low. Regulating businesses that cater directly to new consumers, such as Walmart, may also end up causing local consumers to pay more for locally-purchased commodities, either in the form of higher prices or time spent getting to groceries. Euclidean zoning rules that 
restrict the location of businesses represent one restraint on business formation, but localities have many business-related regulations that are less inherently spatial.

Americans debated local rules for much of the $20^{\text {th }}$ century. Many of the great legal battles of the late $19^{\text {th }}$ and early $20^{\text {th }}$ century followed the decision of states - only rarely lower jurisdictions - to regulate working conditions for reasons other than public safety. The first battles were over physical working conditions, such as Samuel Gompers' fight against tenement house cigar making in New York City, which was banned by the New York State legislature in 1883, after heavy support from the young Theodore Roosevelt.

Yet while there is extensive literature on the impact of land use regulations, the literature on the effects of business regulations is far less developed. Objectivity and rigor are of course essential here. There is no domestic equivalent to the World Bank's Doing Business report, which measures the cost and number of permits required to open a firm in cities throughout the world (although the U.S. Chamber of Commerce Research Association is developing such a measure). Many of the studies of state-level regulation have examined the correlation between some aggregate measure of business-friendliness and economic growth, and while these results can be suggestive, it is hard to draw anything definitive from such course. More compelling evidence has come from the study of particular rules, such as branch-banking regulation (Jayaratne and Strahan, 1996), where it does appear that some regulations are capable of restricting economic growth. We have referred to occupational licensing requirements, which sometimes seem to be an effort to restrict entry, and to insulate existing providers, under a public interest veneer.

One particularly notable form of geographic variation is that after the 1947 TaftHartley Act, many states passed Right-To-Work laws, which prohibit firms from signing "Union Shop" agreements, which require them to fire workers who refuse to pay at least some portion of their union dues. Holmes (1997) compared neighboring counties and found that manufacturing increased substantially after 1947 on the pro-business side of state lines.

We take no stand on whether these myriad state and local rules have benefits that exceed the costs. We do, however, emphasize that these rules have accreted over centuries, and were generally issued with no serious cost-benefit analysis whatsoever. In many cases, the effects of the rules may be so minor that serious review is not worth that effort, but in other cases, it is surely appropriate to weigh measurable costs against benefits, both for new legislation and for existing rules. We now sketch a plausible structure for such a process.

\section{What States and Local Governments Might Do}

We believe that states could well benefit from some version of an Office of

Regulatory Affairs, charged with the goals of ensuring that regulations survive some kind 
of cost-benefit test, of promoting interagency coordination, and of increasing accountability. But there are several important issues of scope and design. (See Appendix, with Executive Order 13563, for relevant principles; that Executive Order is best read in conjunction with Executive Order 12866, which sets out the relevant institutional requirements in detail.)

\section{A. State or Local?}

Few localities in the country have the depth of personnel needed to create an Office of Regulatory Affairs. New York City surely can, and perhaps Chicago and Los Angeles, but such an administrative task becomes infeasible once we move to smaller areas. Moreover, the similarity between smaller localities means that highly localized offices would be duplicating tasks, rather than building up a common bank of expertise. There is also a risk that localized offices would tend to focus on very local costs and benefits, and ignore benefits that occur beyond the area's borders. Finally, since all localities face an overlapping of state and local regulations, it might be difficult for a purely local office to have the perspective to consider how such regulations fit together.

For these reasons, we believe that the natural home for any office of regulatory evaluation is the state, not the locality. States have greater resources and a wider perspective. Moreover, since city governments all fundamentally operate under state law, there would typically be no legal problem with requiring local regulations to follow the guidance of a state-wide officer, as there would be if the Federal government attempted to make state level regulations subservient to Washington's cost-benefit analysis. For example, much of the local zoning in the U.S. was made possible only because states passed standard enabling legislation, such as Massachusetts Chapter 40A. It is clearly within the state's power to require changes in local codes to adhere to state-mandated norms of cost-benefit analysis. To be sure, some legal changes might well be necessary for this structure to be put in place.

In many cases, the state itself may be too small rather than too large an entity to evaluate new regulations. Regulations in New York City affect northern New Jersey and vice-versa. Regulations in Philadelphia affect Camden. Restricting housing supply in coastal California may affect the entire nation. Yet, even though states are surely imperfect implementers of such analysis, they are the institutions at hand, and state-level analysis seems better than any other option.

\section{B. Regulation, Legislation, or Both?}

OIRA's powers are limited to reviewing executive branch regulations; it does not analyze or constrain legislative enactments. We believe that it would be deeply regrettable if any state evaluation office limited itself to regulations. We envision a structure in which the relevant office would have OIRA-like authority over regulations, but an advisory and consultative role in connection with legislative proposals. 
At the national level, OIRA's limited role allows it to do a great deal, for the federal government has a large number of agencies, such as the Department of Transportation, the Department of Health and Human Services, the Department of Agriculture, and the Environmental Protection Agency, all of which have been given broad regulatory powers. To be sure, there do exist many local or state counterparts. We have already discussed the definitional control over wetlands ceded to the Massachusetts Environmental Protection Commissioner, and at the local level, zoning administration is often ceded to agencies such as the New York City Department of City Planning or the Boston Redevelopment Agency. Still, much of state and local regulation comes directly from state law or local ordinance. Limiting oversight to the executive branch would leave most local regulations untouched.

We believe that it would be most effective to have a single entity, charged by state law to make assessments of executive branch regulations, state laws, and local legislative actions. It is easy to imagine state legislation that essentially forbid executive and local regulations that failed to be approved by this agency. All the same, the legislature is unlikely to bind itself in that way, and it would have legitimate reasons for declining to do. A feasible structure would be one in which the agency could offer a nonbinding analysis of proposed legislation. Even if it would not be binding, the analysis would undoubtedly play a significant role in legislative deliberations. The European Union now follows a model of this sort.

If the office is evaluating legislative proposals, as we suggest, then not only OIRA but also the Congressional Budget Office (CBO) becomes a model for its operations. Over the last forty years, the $\mathrm{CBO}$ has maintained a reputation for impartial integrity and sound analysis through Democratic and Republican administrations and leadership. Several features of the CBO structure are worth highlighting. Both branches of the legislature need to approve the CBO director, and they have the power to dismiss him or her. The position is at least nominally made without attention to political party. These would all be desirable features in a local agency as well.

The CBO, however, does differ from OIRA along a major dimension directly relevant to our proposal. Its goal is to evaluate the budgetary impact of different forms of legislation, not overall costs and benefits, and its evaluations are constrained by very rigid rules. For example, the budget projections often assume no further changes in tax laws, even when those changes are highly likely. Cost-benefit analysis, as opposed to projecting budgets, is typically more difficult and more holistic. We suspect that CBO personnel may indeed be quite helpful in providing support and assistance for nascent state-level evaluation groups, but it needs to be recognized that the task is somewhat different.

\section{Minimalism and Maximalism}

State governments are highly diverse in terms of their capacities and their needs, and a one-size-fits-all model does not make sense. But for state and local governments, a great deal would be gained by adapting some version of the original Reagan model, with 
its two simple components: an oversight process and a substantive requirement of costbenefit balancing. For both components, minimalist and maximalist versions can easily be imagined.

A minimalist version would involve the creation of some kind of technical capacity, reposed perhaps in a small group or office, whose task would be to scrutinize the most significant, burdensome, or controversial rules and to give them some kind of reality check. A commitment to an assessment of costs and benefits, to be produced by officials in that office or in the office or agency that seeks to impose the rules, could ensure that the reality check is real. Under the minimalist approach, the small office, combined with that commitment, could help to deter unjustified requirements and to ensure that officials are focused on what really matters, which is the human consequences of their actions.

A maximalist version would involve something closer to what the national government does now. States and cities could create their own Offices of Regulatory Affairs, consisting of people with a degree of economics training, enabling them to produce, or at least to scrutinize, careful analysis of costs and benefits. For certain rules perhaps those anticipated to cost more than \$25 million annually - relevant officials might be required to produce a full-scale regulatory impact analysis, akin to what now emerges from the Federal government. The length and depth of the analysis would be a function of the cost and importance of the particular regulation.

We much prefer the maximalist model, because it is most likely to prevent harmful outcomes, but we recognize that some states will lack both the will and the capacity, and a degree of experimentation is highly desirable. Some states might do well to "pilot" the minimalist model and to build on it if it works well.

\section{The Nature of Cost-Benefit Analysis}

1. Basic issues. What would cost-benefit analysis look like at the state and local level? For many questions, the approach would be essentially identical to that used at the federal level, and should be based on the same tools and techniques. OMB Circular A-4 (http://www.whitehouse.gov/omb/circulars_a004_a-4), supplemented by various guidance documents (including a primer, http://www.whitehouse.gov/sites/default/files/omb/inforeg/regpol/circular-a4_regulatory-impact-analysis-a-primer.pdf, and a simple checklist, http://www.whitehouse.gov/sites/default/files/omb/inforeg/regpol/RIA_Checklist.pdf), outlines those tools and techniques. Air pollution controls, for example, might borrow directly on what is now done by the EPA, and highway safety regulation could draw on the longstanding work of the Department of Transportation. But some domains present special challenges.

The well-defined area of land use regulation is an example. Consider a decision to raise the minimum lot size in a community for new construction from one to two acres. The potential beneficiaries from this rule would be the community members who gain 
from lower levels of congestion, possibly a nice view when walking or driving, and possibly less financial burden on their local public services. These local benefits could be estimated directly or indirectly inferred through land values. A long intellectual tradition argues that local amenities and tax obligations are captured in land values, so an assessment of the link between new construction and property values provides one means of assessing the upside of the regulations.

On the downside, the new regulation will take from owners who would like to subdivide their property, potentially reduce tax revenues, and potentially add to congestion if restricting development close to the city center pushes building further away. There are also potentially local environmental benefits of lower density that need to be offset against the environmental losses of pushing buildings further away. These calculations are not simple, but they are doable, and once an agency has developed a template for these calculations, they can easily be repeated in multiple jurisdictions.

A state-wide cost-benefit agency will not have the resources to examine every single form of legislation. We have suggested that as at the national level (with the threshold of $\$ 100$ million in economic impact), it makes sense to have a minimum threshold needed for evaluation, based on a preliminary investigation of the regulation. However, unlike at the national level, the threshold should also be based on repetition. One community's change in zoning laws might not meet a minimum lower threshold on costs, but when repeated hundreds of times by different areas, the threshold would certainly be hit. For this reason, it makes more sense to have a minimum threshold based on the total number of cases for which the developed methodology is useful.

2. Challenges for quantification. It also makes sense to recognize risk and uncertainty. States can reflect their preferences around these issues in different ways. A state that was particularly fearful of regulatory overreach might set the bar at parity between costs and benefits, or even require benefits to exceed costs by some minimal amount. Alternatively, a state that wished to err on the side of certain safeguards for safety, health, and the environment might allow regulations to proceed as long as estimated costs were no more than 10 percent higher than benefits.

These statements all concern the average or expected levels of costs and benefits, and in many cases, there will be some possibility that costs or benefits will differ widely from the main projection. We suspect that the complexity of risk-adjusted scoring rules could just be too great, but it is certainly possible to have rules that give more weight to particularly bad outcomes than to particularly good outcomes. OMB Circular A-4 offers some guidance on this question.

How should the agency deal with hard-to-quantify costs and benefits, such as protection of privacy, building access for those who use wheelchairs, or the religious benefits allegedly associated with blue laws? The national government has a great deal of experience with this question. The standard approach involves "breakeven analysis" (Sunstein, 2014), by which agencies ask: How high would the non-quantified benefits have to be to justify the costs? 
Suppose, for example, that the EPA is considering a water pollution rule that would cost $\$ 1$ billion and deliver $\$ 200$ million in quantifiable benefits (say, in terms of human health and improved recreation), but that would also produce significant nonquantifiable benefits (in terms of, say, ecological benefits). Relevant questions would be: How many water bodies? What kinds of improvements? What would those improvements actually achieve? Would they help human beings and, if so, how? Suppose that the number of water bodies is not large, that the improvements are relatively modest, and that for human beings, those benefits do not do a great deal of good. If so, an expenditure of $\$ 1$ billion would not be easy to defend, assuming that the quantifiable benefits are in the range of $\$ 200$ million. Unless the law required the agency to proceed, the rule would encounter serious questions.

Suppose, by contrast, that once we investigate the details, we find that the rule would make a large difference - for example, because it would protect a numerous water bodies, and do a great deal for them, with a wide range of aesthetic and ecological benefits (including the protection of fish and wildlife). If, we may have enough to justify a serious discussion. A similar analysis could be applied to a wide range of regulations with benefits that are difficult or impossible to quantify. Consider, for example, laws protecting disabled people against discrimination or safeguarding personal privacy (Sunstein, 2014).

In some cases, the problem of apparent nonquantifiability becomes more tractable if the state has alternative means of achieving the same ends. For example, a specific goal for the protection of wildlife might be achievable either by restricting development in the denser and more economically active section of a state or by increasing the size of a state park in a less dense area. Other things being equal, the less expensive means should be chosen.

To be sure, some problems present exceedingly difficult challenges, for which economic analysis cannot have the final word. But the federal experience suggests that these challenges should not be overstated - and that quantitative analysis can operate as an indispensable check on decisions that might otherwise be based on intuitions, anecdotes, or interest-group pressures.

\section{Conclusion}

No one should deny that regulation can do a great deal of good, not least by lengthening lives. But if it is poorly designed, it can jeopardize a wide range of social goals, reducing economic growth, harming small businesses, and squelching innovation. For all its limitations, cost-benefit analysis is the most disciplined way to test whether regulatory requirements are a good idea. At the national level, its track record establishes its ability to separate the wheat from the chaff - to make the case for sensible mandates (even in the face of political opposition) and to decrease the likelihood that regulatory initiatives will be ill-directed. 
It is remarkable but true that nearly thirty-five years after President Reagan established what has proved to be an enduring national commitment to such analysis, state and local governments have shown, at most, sporadic efforts in its directions. This is ironic, because such governments are best positioned to experiment with new institutional forms - and to develop models from which other states, and the federal government itself, can learn. In a period of economic difficulty, to which ill-conceived regulations sometimes contribute, there is new urgency for institutional reform at the state-level, in the form of an endorsement of Regulatory Moneyball. 


\section{Appendix}

\section{Executive Order 13563 of January 18, 2011: Improving Regulation and Regulatory Review}

By the authority vested in me as President by the Constitution and the laws of the United States of America, and in order to improve regulation and regulatory review, it is hereby ordered as follows:

Section 1. General Principles of Regulation. (a) Our regulatory system must protect public health, welfare, safety, and our environment while promoting economic growth, innovation, competitiveness, and job creation. It must be based on the best available science. It must allow for public participation and an open exchange of ideas. It must promote predictability and reduce uncertainty. It must identify and use the best, most innovative, and least burdensome tools for achieving regulatory ends. It must take into account benefits and costs, both quantitative and qualitative. It must ensure that regulations are accessible, consistent, written in plain language, and easy to understand. It must measure, and seek to improve, the actual results of regulatory requirements.

(b) This order is supplemental to and reaffirms the principles, structures, and definitions governing contemporary regulatory review that were established in Executive Order 12866 of September 30, 1993. As stated in that Executive Order and to the extent permitted by law, each agency must, among other things: (1) propose or adopt a regulation only upon a reasoned determination that its benefits justify its costs (recognizing that some benefits and costs are difficult to quantify); (2) tailor its regulations to impose the least burden on society, consistent with obtaining regulatory objectives, taking into account, among other things, and to the extent practicable, the costs of cumulative regulations; (3) select, in choosing among alternative regulatory approaches, those approaches that maximize net benefits (including potential economic, environmental, public health and safety, and other advantages; distributive impacts; and equity); (4) to the extent feasible, specify performance objectives, rather than specifying the behavior or manner of compliance that regulated entities must adopt; and (5) identify and assess available alternatives to direct regulation, including providing economic incentives to encourage the desired behavior, such as user fees or marketable permits, or providing information upon which choices can be made by the public.

(c) In applying these principles, each agency is directed to use the best available techniques to quantify anticipated present and future benefits and costs as accurately as possible. Where appropriate and permitted by law, each agency may consider (and discuss qualitatively) values that are difficult or impossible to quantify, including equity, human dignity, fairness, and distributive impacts.

Sec. 2. Public Participation. (a) Regulations shall be adopted through a process that involves public participation. To that end, regulations shall be based, to the extent feasible and consistent with law, on the open exchange of information and perspectives 
among State, local, and tribal officials, experts in relevant disciplines, affected stakeholders in the private sector, and the public as a whole.

(b) To promote that open exchange, each agency, consistent with Executive Order 12866 and other applicable legal requirements, shall endeavor to provide the public with an opportunity to participate in the regulatory process. To the extent feasible and permitted by law, each agency shall afford the public a meaningful opportunity to comment through the Internet on any proposed regulation, with a comment period that should generally be at least 60 days. To the extent feasible and permitted by law, each agency shall also provide, for both proposed and final rules, timely online access to the rulemaking docket on regulations.gov, including relevant scientific and technical findings, in an open format that can be easily searched and downloaded. For proposed rules, such access shall include, to the extent feasible and permitted by law, an opportunity for public comment on all pertinent parts of the rulemaking docket, including relevant scientific and technical findings.

(c) Before issuing a notice of proposed rulemaking, each agency, where feasible and appropriate, shall seek the views of those who are likely to be affected, including those who are likely to benefit from and those who are potentially subject to such rulemaking.

Sec. 3. Integration and Innovation. Some sectors and industries face a significant number of regulatory requirements, some of which may be redundant, inconsistent, or overlapping. Greater coordination across agencies could reduce these requirements, thus reducing costs and simplifying and harmonizing rules. In developing regulatory actions and identifying appropriate approaches, each agency shall attempt to promote such coordination, simplification, and harmonization. Each agency shall also seek to identify, as appropriate, means to achieve regulatory goals that are designed to promote innovation.

Sec. 4. Flexible Approaches. Where relevant, feasible, and consistent with regulatory objectives, and to the extent permitted by law, each agency shall identify and consider regulatory approaches that reduce burdens and maintain flexibility and freedom of choice for the public. These approaches include warnings, appropriate default rules, and disclosure requirements as well as provision of information to the public in a form that is clear and intelligible.

Sec. 5. Science. Consistent with the President's Memorandum for the Heads of Executive Departments and Agencies, "Scientific Integrity" (March 9, 2009), and its implementing guidance, each agency shall ensure the objectivity of any scientific and technological information and processes used to support the agency's regulatory actions.

Sec. 6. Retrospective Analyses of Existing Rules. (a) To facilitate the periodic review of existing significant regulations, agencies shall consider how best to promote retrospective analysis of rules that may be outmoded, ineffective, insufficient, or excessively burdensome, and to modify, streamline, expand, or repeal them in accordance 
with what has been learned. Such retrospective analyses, including supporting data, should be released online whenever possible.

(b) Within 120 days of the date of this order, each agency shall develop and submit to the Office of Information and Regulatory Affairs a preliminary plan, consistent with law and its resources and regulatory priorities, under which the agency will periodically review its existing significant regulations to determine whether any such regulations should be modified, streamlined, expanded, or repealed so as to make the agency's regulatory program more effective or less burdensome in achieving the regulatory objectives. 


\section{References}

CBRE/Grossman Retail Advisors. 2013. "The Ferdinand: Retail/Restaurant Opportunity." < http://www.dudleyvision.org/wpcontent/uploads/2014/01/The_Ferdinand_retail_brochure.pdf $>$

Coglianese, Cary, Adam M. Finkel, and Christopher Carrigan, eds. 2014. Does Regulation Kill Jobs? University of Pennsylvania Press.

DeMuth, Christopher C., and Douglas H. Ginsburg. 1986. "White House Review of Agency Rulemaking.” Harvard Law Review, 99(5): 1075-1088.

Gaffin, Adam. 2013. "City councilors want liquor licenses for Dudley Square." Universal Hub $<$ http://www.universalhub.com/2013/city-councilors-want-liquor-licensesdudley-square $>$

Glaeser, Edward L., Joseph Gyourko, and Raven Saks. 2005. "Why have housing prices gone up?" NBER Working Paper 11129.

Glaeser, Edward L., and Matthew E. Kahn. 2010. "The Greenness of Cities: Carbon Dioxide Emissions and Urban Development." Journal of Urban Economics, 67(3): 404-418.

Glaeser, Edward L., Sari Pekkala Kerr, and William R. Kerr. 2012. "Entrepreneurship and Urban Growth: An Empirical Assessment with Historical Mines." NBER Working Paper 18333.

Glaeser, Edward L., and Bryce A. Ward. 2009. "The Causes and Consequences of Land Use Regulation: Evidence from Greater Boston." Journal of Urban Economics, 65(3): $265-278$.

Greenstone, Michael. 2009. "Toward a Culture of Persistent Regulatory Experimentation and Evaluation1." New Perspectives on Regulation, David Moss and John Cisternino, eds., Cambridge, MA: The Tobin Project.

Heinzerling, Lisa. 2013. "Inside EPA: A Former Insider's Reflections on the Relationship between the Obama EPA and the Obama White House." Pace Environmental Law Review (forthcoming).

Holmes, David, ed. 1997. Virtual Politics: Identity and Community in Cyberspace. Vol. 448. Sage. 
Jayaratne, Jith, and Philip E. Strahan. 1996. "The Finance-Growth Nexus: Evidence from Bank Branch Deregulation." The Quarterly Journal of Economics, 111(3): 639670 .

Kahan, Dan. 2010. "Fixing the Communications Failure." Nature, 463(7279): 296-297.

Kahneman, Daniel. 2011. Thinking, Fast and Slow. New York: Farrar, Straus and Giroux.

Katz, Lawrence, and Kenneth T. Rosen. 1987. "The Interjurisdictional Effects of Growth Controls on Housing Prices." Journal of Law and Economics, 30: 149-160.

Lewis, Michael. 2003. Moneyball: The Art of Winning an Unfair Game. WW Norton \& Company.

McGarity, Thomas O. 2013. "EPA at Helm's Deep: Surviving the Fourth Attack on Environmental Law." Fordham Environmental Law Review, 24: 205-275.

Morgenstern, Richard. Economic Analysis at EPA: Assessing Regulatory Impact. Washington: Resources for the Future.

Novak, William J. 1996. People's Welfare: Law and Regulation in Nineteenth-Century America. Univ of North Carolina Press.

Sunstein, Cass R. 2013a. Simpler: The Future of Government. New York: Simon and Schuster.

Sunstein, Cass R. 2013b. "The Office of Information and Regulatory Affairs: Myths and Realities." Harvard Law Review, 126: 1838-1878.

Sunstein, Cass R. 2014. Valuing Life. Chicago: University of Chicago Press.

"To Revive City's Main Streets, Get More Liquor Licenses." Editorial. The Boston Globe 01 July 2013: n. pag. www. bostonglobe.com. 
